\title{
Modeling of the effects of climate change on rainy and gully erosion potential of Kor-chamriz watershed in Fars province
}

\author{
${\text { Gholamreza } \operatorname{Roshan}^{1} \cdot \text { Saeed Negahban }}^{2}$
}

Received: 13 August 2015/Accepted: 19 August 2015/Published online: 7 September 2015

(C) Springer International Publishing Switzerland 2015

\begin{abstract}
Role of climatic factors is significant among the factors affecting the erosion of watersheds. The importance of this issue increases with regard to the phenomena of climate change. Therefore in this study using different scenarios of climate change, rainy and gully erosion potential of Kor-chamriz watershed in Fars province was studied applying Arnoldus and Sepaskhah's methods of humidity-soil for statistical period of 2002-2060. It should be noted that he output of general circulation climate models (HadCM3) were used to stimulate temperature and precipitation data and they were downscaled using Lars-WG software. Results of this study show that the based on scenarios of A1B and A2, basin's precipitation will increase and according to various scenarios, the annual temperature changes for the stimulated period have increased 0.32-0.51 degrees in comparison with the basic period. Then, every three scenarios of climate change, especially A1B indicates an increase in the potential of gully erosion occurrence based on WS index compared to the basic period. The Results of this study show that according to the statistics of basic period of 1988-2010, the ratio between extracted rainy erosion from Arnoldus formula to the real erosion data has been $19 \%$ that this amount was calculated to be $3 \%$ for Sepaskhah method. Also all scenarios of future climate change confirm decreasing trend of rainy erosion based on two observational methods and three proposed climate change
\end{abstract}

Gholamreza Roshan

ghr.roshan@gu.ac.ir; r.rowshan@yahoo.com

Saeed Negahban

snegahban@shirazu.ac.ir

1 Department of Geography, Golestan University, Gorgan, Iran

2 Department of Geography, Shiraz University, Shiraz, Iran scenarios. Therefore, it is expected that in the coming decades the ratio of rainy erosion compared with real erosion of the whole basin will decrease.

Keywords Modeling $\cdot$ Climate change $\cdot$ Hydro climatology $\cdot$ Erosion $\cdot$ Kor-chamriz watershed

\section{Introduction}

Erosion is a continuous process which has existed since the formation of lands and human's dong husbandry and agriculture and it has caused a change in the shape of lands as they are seen today. Obviously, due to lack of facilities for controlling erosion from one hand and constant human intervention in exploitations of soil, water and plant resources from the other hand, this trend will continue in the future. Meanwhile, aggravated erosion is a phenomenon which is caused by unconscious and profit-seeking human interventions in nature and result in soil degradation, the soil which is considered the world's production base. Soil erosion by water has been described as one of the main causes of land degradation in a wide range of environments (Valentin et al. 2005.132; Zucca et al. 2006, 87; Bou kheir et al. 2007, 1770). The phenomenon of gully erosion is considered as a common process in the loss of soil resources (Cheng et al. 2006,184 ) and in the form of aggravated erosion as one of the most important processes of land degradation, causes limitations on land use, development of bad lands and barn lands and an increase in sedimentation in water reservoirs (Bouchnak et al. 2009, 170). With more erosion of the bed and head of the gully and collapse of gully 's walls, this kind of erosion expands and develops (Kirkby et al. 2009, 1841) and all the eroded materials can enter the river system and intensify the effects of external damage of water erosion 
(Posesen et al. 2003, 91). Several factors are involved in the formation and development of the gullies. Vanwalleghem et al. (2008) have considered factors such as upstream slope of landform, formation, the amount of minerals, an increase of more than $13 \mathrm{~mm}$ of rainfall in $24 \mathrm{~h}$, fine materials, the condition of drainage in the upstream of gully and solubility of the formation as being effective in the development and expansion of landforms. Zachar $(1982,584)$ states that most of the gullies in Czechoslovakia have formed at the slope of 10 degrees and $90 \%$ of them are formed at the slope of $2^{\circ}-$ $15^{\circ}$. Gabris et al. (2003a, b, 151) have reported that gully erosion has decreased significantly after deforestation of lands. Kirkby and Bull studies $(2000,126)$ have shown that factors contributing to the occurrence of gully erosion vary from region to region. Gullies as geomorphological shapes, with their development from head and the collapse of materials from the sides, enter domain materials and in fact the only cultivable soil of the mountains into valleys and in this way, they flow an abundance of domain soil towards flowing waters (Whiteford et al. 2010) and with the increasing of gullies' depth at the bottom, domains are extremely disturbed and locate significant deposits in the flowing waters (Gabet and Booktev 2008, p. 302 and Kasali 2006, p. 128). Gully erosion has attracted much attention in recent years by holding six international conferences from 2000 to 2013 . Researchers studied several factors in relation to the gully erosion. Gabris et al. (2003a, b) compared the gully and land use maps in 1784, 1860, 1920 and 1994 and studied the relationship between formation and growth of the gullies with land use change and domain slope in Hungary. The results showed that by 1860 , more than $50 \%$ of the area was covered with forests, average growth in the gully was $5 \mathrm{~m}$ square kilometer in a year and in 1994 when the forest cover was reduced to about $25 \%$ and agriculture expanded to slopes more than $25 \%$, the average rate of gully growth reached to 10 meters square kilometers per year. Posesen et al. (2003) in a study showed that rainfall threshold for gully growth in the areas with forest cover is higher than the rainfall threshold for the growth of temporary gullies in the agricultural areas and surfaces with natural vegetations in a humid environment are resistant to the erosion of concentrated surface currents and are sensitive to gully erosion only when they have experienced maximum precipitation or climate change in a timescale of 1000 years or higher. Valentine et al. (2005) in their research showed that gullies are not limited to marn areas but globally they take place in soils which are close to crusting such as los, sandy soils or in soils which are likely to have piping erosion such as dispersive soils. According to this research gully erosion is often caused or intensified by inappropriate land use and occurrence of maximum precipitation and continue producing deposits for a long time after the cease of causing factors. Zucca et al. (2006) studied the effects of land use and landscape on spatial distribution and geomorphological shapes of gullies in agriculture - animal husbandry areas of Italy. In a combined methodology, by using aerial photographs and field surveys, they calculated the Relationships between morphological parameters of various gullies and then determined the relationship between morphological shapes of a gully and environmental features such as layers of geology, slope, land capability and land use. Bouchnak et al. with the study of 8 basin likely to have water erosion in Tunisia, calculated the volume of deposits formed byvertical forehead and wallsgullies floor by processing 5 periods of aerial photographs from 1952 to 2000 . The results show that in each period, two main processes of gully erosion (erosion of vertical forehead and walls-floor) increase significantly with domain slope. Erosion of walls-floor helps more than the erosion of vertical forehead to the total load of gully deposits. Total gully erosion in mild domains have been calculated to be 1.66 cubic meters per hectare per year and in the domains with steep slopes it would be 5.603 cubic meters per hectare per year. Vanwalleghem et al. (2008) studied 43 permanent gullies in Meerdaal forest area in Belgium in the form of the studies of old geomorphological shapes. These researchers using logical regression model and natural and human variables including soil type, domain slope, slope direction, elevation from sea level, distance from roads, level of drainage, stream power index, distance from archaeological sites and distance from human structures analyzed factors controlling old gullies of the studied area. The results show that both physical and human factors are important in the distribution of the gullies and logical regression model is very important in the prediction of gully occurrence. Luca et al. (2011) used statistical methods by applying GIS in the estimation of sensitivity to gully erosion in Turbolo basin in Italy. Models' efficiency was predicted by using the predicted curves and they were evaluated by comparing each level of sensitivity with gully distribution. The results show that although all models are relatively efficient but Logical multivariate regression model was recognized as the best model in predicting sensitivity to gully erosion of the studied area. In this study the gully and rainy erosion potential have been studied with regard to climate change in Kor-chamriz watershed. Distinction and innovation of this study, compared to the above-mentioned studies is the investigation of the effects of climate change and also the future.

\section{Introduction of the study area}

Kor-chamriz basin is located in the southern half of the country and to the north of Shiraz province. The relative position of this basin is along Kor River from Khaniman village to the downstream of crossing point of Salty and Sweet River. This basin is located in the cities of Marvdasht, Saadat Shahr, Safashahr and Eghlid with $154 \mathrm{~km}$ 
distance from Shiraz. This basin is located at a an eastern longitude of $52^{\circ}, 01 \mathrm{~min}$ and $46 \mathrm{~s}$ to $52^{\circ} 14 \mathrm{~min} 31 \mathrm{~s}$ and a northern latitude of $30^{\circ} 25 \mathrm{~min} 02 \mathrm{~s}$ and $30^{\circ} 36 \mathrm{~min} 57 \mathrm{~s}$. Basin's area is about 738 square kilometers that majority of it are mountains and hills (Fig. 1). Geomorphologically, it is a part of folded Zagros with a minimum height of 1690 meters and a maximum height of 3702 meters from sea level. Stones of this area are of sandstone and limestone type that Asmari limestone is dominant. The highest points are located in the western part of the basin. The vegetation in the study area is almost poor and there are no sustainable plants except for scattered plants of Artemisia, Asteragalous and Almondos and Pistachios Trees families.

\section{Materials and methods}

Generally the present study investigates the effect of climate change on gully and rainy erosion potential of Korchamriz watershed for two periods including the basic period (past up to the present) and the next decade. Therefore the data of the basic period is observational and it is simulated for the next decades. Also the data consisted of two groups of climatic data of temperature and precipitation for the period of 1988-2010 which was related to Dorodzan dam station in the studied watershed and were provided by Iran Meteorological Organization and observational data of sediment study for study period of 1991-2010 which were gathered from Watershed Research Center of Fars province. It is worth noting that observational data of sediment study were extracted from three stations of Chamriz, Khaniman and Tang which are scattered throughout the basin.

\section{Fluctuations in soil moisture (determination of WS index)}

Researchers usually use different climatic coefficients to find out the potential of gully occurrence in hydrographic basins. Valuable research has been done by (Oostwoud et al. 2011; Zucca et al. 2006; Archibold 2003) in this regard. Coefficient HydroThermal and Soil Wetness Coefficient are two simple and important presented coefficients. WS index can be used to evaluate areas potential for linear erosion of flowing waters (especially gully erosion) (Eq. 2). This equation is used in the present study because months with negative

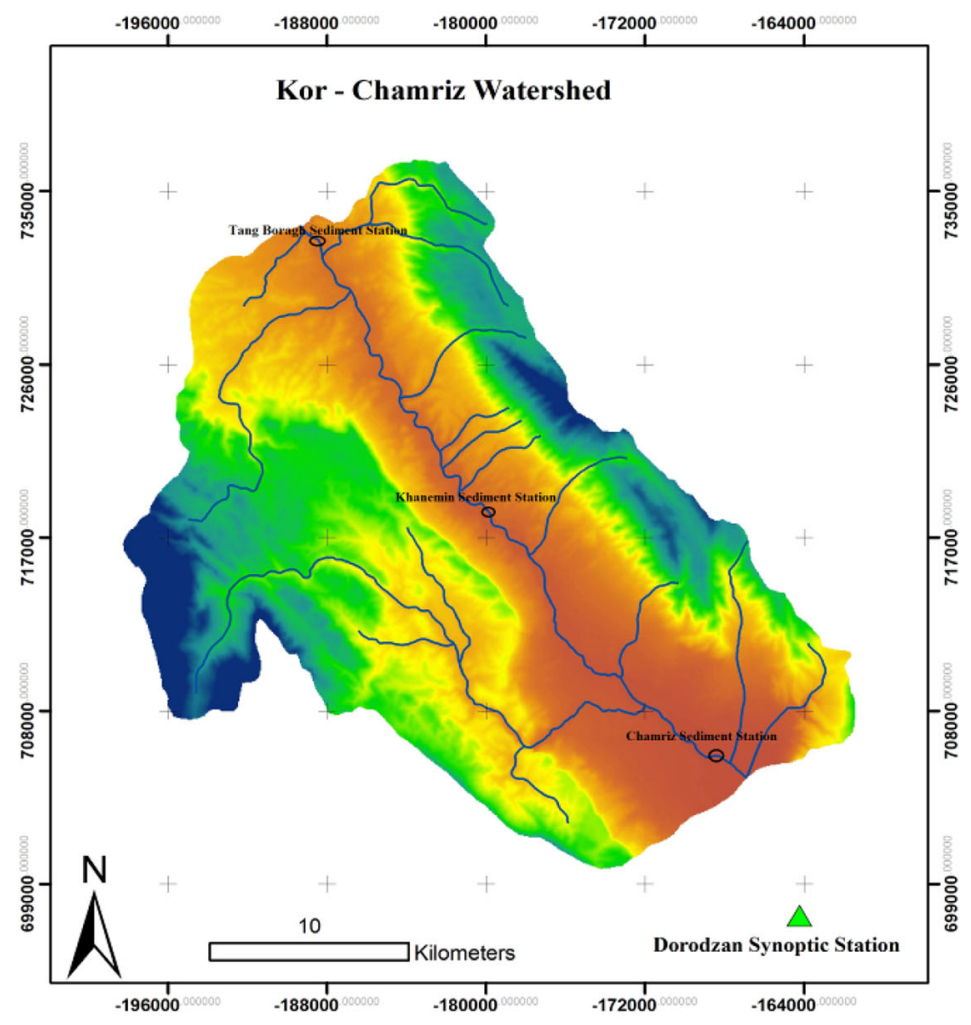

Fig. 1 The location of Kor-chamriz basin

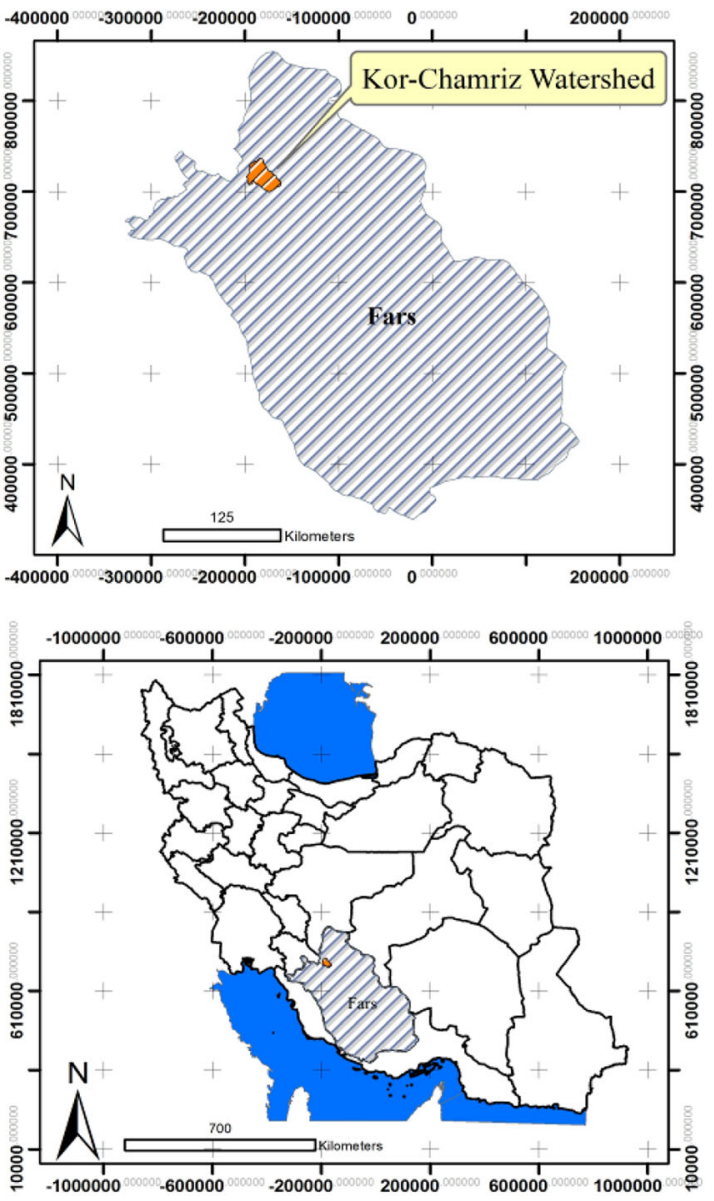


output of WS have more potential for the occurrence of linear erosion (especially gully erosion). Thus in the present article, WS index changes are analyzed for basic period and the future decade period.

$\mathrm{WS}=\left(\mathrm{R}-\mathrm{R}_{\mathrm{P}}\right) / \mathrm{T}$

$\mathrm{R}_{\mathrm{P}}=30 \times(\mathrm{T}+7)$

$\mathrm{WS}=$ fluctuations in soil moisture, $\mathrm{R}=$ average amount of rainfall in millimeters, $\mathrm{RP}=$ coefficient of temperature, $\mathrm{T}=$ temperature in Celsius per month.

\section{Indices of rain erosion}

In this paper to estimate the amount of erosion and sediment yield per hectare as an index of rain erosion Arnoldus empirical formula (Eq. 4) and Sepaskhah native formula (Eq. 5) have been used.

$E I=0.302\left(\frac{\sum^{N} p i^{2}}{P}\right)^{1.93}$

$E I=1.6\left(\frac{\sum^{N} p i^{2}}{P}\right)^{1.27}$

$\mathrm{EI}=$ average rain erosion index based on ton in hectare, $\mathrm{Pi}=$ average monthly rainfall in millimeters, $\mathrm{P}=$ the average annual rainfall in millimeters, $\mathrm{N}=$ number of months when precipitation has occurred.

\section{Modeling of climatic components}

To simulate climatic conditions of the next decades, various scenarios and public models of climatic circulation have been defined. Since the spatial resolution of public models of climatic circulation is very low, it is needed to change them into smaller spatial scale and to perform downscaling. In general, there are two dynamic and statistical methods or a combination of them for downscaling that various models have been created based on them. In statistical methods, a relationship is established between output parameters of AOGCM model and Climatic elements such as precipitation and temperature in a daily scale. Given that output parameters of models are average representative of a whole cell (in HadCM3 model, 3.75 by 2.5 latitude and longitude), therefore the accuracy of spatial generalization of models for stations located in different points of a cell can be different (Roshan and Grab 2012). In this study to simulate the values of temperature and precipitation for the period of 2020-2060 HadCM3 model outputs were used and based on emission scenarios, the family of three scenarios of A1B, A2 and B1 have been used. Also in order to downscale climatic data a weather generator entitled LARS-WG version 5.5 was used. LARS-WG stimulates future climatic data under the current conditions of a station. This model uses an accidental weather generator from observed weather of a station to calculate a set of parameters for probable distribution of climatic variables. This set of parameters is used to produce time series of fictitious climatic variables with a desired length by random selection of values of appropriate distributions.

With the involvement of distribution parameters for a station along with climatic predicted changes which are resulted from global or regional climatic models, daily climatic scenario can be created for this station. In this article, initially the output of the LARS-WG for the period of 1988-2010 were simulated and then the simulated values were evaluated according to various statistical tests such as RMSE, MAE, $\mathrm{MBE}$ and R2 with actual data for the same period in order to determine the efficiency of LARS-WG model and the reliability of simulated data for the next decades. Since in all years the average annual standard deviations of all variables are lower than the standard deviation of the statistical period and it is expected that climatic limit values increase in the future, in order to resolve this shortcoming using Eqs. 5 and 6 while maintaining the means, standard deviation of these variables are increased in the basic period with the ratio of the standard deviation of observed data to the simulated data by the model of the past period.

$F_{f u t}=F_{o b s}+\left(F_{G C M}^{f u t}-F_{G C M}^{\text {base }}\right)$

$S T D=\frac{S T D_{\text {base }}^{\text {obs }}}{S T D_{\text {base }}^{G C M}} \times S T D_{\text {fut }}^{G C M}$

In which $F_{G C M}^{o b s}, F_{G C M}^{b a s}, F_{o b s}, F_{f u t}$ represent predicted variables, observed variables, predicted on the network model in the future period and simulated on the network model in the past period. And then by maintaining the mean, their standard deviations were calculated based on Eq. 6 in which STD is the deviation of climatic variable (Babaeian et al. 2007).

\section{Research findings}

\section{Validation of the simulated output by climatic generator}

The results of the simulated data by the model and the actual data of the basic period (1988-2010) are shown in Table 1. The determination coefficient was high for all variables $(\mathrm{R} 2=0.99)$. Error measurement indices including mean absolute error, mean bias error and mean square 
Table 1 The evaluation of the model based on the period of 1988-2010 according to statistical tests

\begin{tabular}{lllcl}
\hline Statistical test & Max-T & Min-T & Radiation & Rain \\
\hline $\mathrm{R}^{2}$ & 0.99 & 0.99 & 0.99 & 0.99 \\
$\mathrm{RMSE}$ & 0.3888 & 0.5155 & 0.6322 & 0.836 \\
MBE & 0.1573 & 0.0041 & -0.0202 & 0.0335 \\
MAE & 0.3888 & 0.5155 & 0.9255 & 0.8382 \\
\hline
\end{tabular}

Table 2 The Values of computational T-test by the model for validation at the level of $5 \%$

\begin{tabular}{lllll}
\hline Months & Max-Tem & Min-Tem & Radiation & Rain \\
\hline Jan & 0.519 & 0.208 & 0.797 & 0.366 \\
Feb & 0.272 & 0.089 & 0.753 & 0.127 \\
Mar & 0.09 & 0.805 & 0.808 & 0.135 \\
Apr & 0.081 & 0.666 & 0.378 & 0.181 \\
May & 0.666 & 0.555 & 0.108 & 0.562 \\
Jun & 0.026 & 0.951 & 0.071 & 0.448 \\
Jul & 0.166 & 0.404 & 0.55 & 0.477 \\
Aug & 0.652 & 0.871 & 0.578 & 0.675 \\
Sep & 0.989 & 0.47 & 0.107 & 0.227 \\
Oct & 0.756 & 0.304 & 0.561 & 0.267 \\
Nov & 0.971 & 0.223 & 0.64 & 0.838 \\
Dec & 0.018 & 0.176 & 0.845 & 0.366 \\
\hline
\end{tabular}

error were small. The values of these variables are always between zero and 1 that smaller values indicate that there are fewer differences (the difference between the observed values and the model in the predicted $t$ test in the statistical model) in the data generation by the model (Table 1). The results of the predicted test of all variables in 12 months of the year indicated the lack of a significant difference of observed values with predicted values in the probability level of $5 \%$ (Table 2). Given that there is no significant difference between predicted values and observed values for the period of 1988-2010, therefore the ability of model for simulation of the future climatic condition was confirmed.

\section{Simulation of temperature and precipitation changes for the future decades}

Initially the results of precipitation simulation for the period of 2020-2060 were compared with the values of this factor for the basic period of 1988-2010. It can be seen in the Fig. 2 that no major changes would happen in the annual rainfall regime so that the minimum rainfall begins from mid-spring and continues to the end of summer. But precipitation maximum of study watershed has concentrated since the beginning of autumn to the early spring. This situation is the same both for the basic period and the three scenarios which have simulated rainfall changes of the future decades. But there are differences for the first four months of the year between the simulated and basic periods. These differences are often in the form of increased amounts of precipitation for the future decade compared to the basic period. The other finding of this section is a change in the average of total annual rainfall. The findings show that the average of annual total show the value of $484 \mathrm{~mm}$ for the basic period that this value has increased $18 \mathrm{~mm}$ for the $\mathrm{A} 1 \mathrm{~B}$ scenario and $24.5 \mathrm{~mm}$ for A2 scenario, but based on the results of B1 scenario, the average of total annual rainfall shows a decrease of $1.1 \mathrm{~mm}$. in the following correlation coefficient was calculated to analyze changes in time series of monthly precipitation based on the basic and simulated period and the outputs are presented in Table 3. According to the time series of the precipitation of the basic period, the only correlation coefficient indicating the existence of significant and decreasing trend belongs to February $r=-0.43$ and other months do not have significant changes. However for the simulated period of 2020-2060 according to A1B scenario, the only significant and decreasing precipitation trend belonged to April with a value of $r=-0.38$ And according to two scenarios A2 and B1, only March indicated the existence of an increasing and significant trend with values of $r=0.35$ and $r=0.34$ and there was no significant trend in other months.

What outputs show about the changes of future decades temperature confirms the increase of average of annual temperature based on all scenarios compared to the basic period of 1988-2010. But in A2 scenario, which is the most pessimistic one, the increase in the temperature compared to the basic period is $0.51^{\circ}$ that this value for two A1B and B1 scenarios is 0.40 and $0.32^{\circ}$ of temperature increase respectively. It can be seen in Fig. 3 that changes in monthly average of the future decades have been very minimal compared to the basic period and there was no change in the movement and annual pattern.

Thus, although the trend of basic temperature change for February, March and June is increasing and significant but these changes are only increasing and significant for May with $\mathrm{r}=0.36$ based on A1B scenario, and based on two scenarios of B1 and A2, July with $r=-0.27$ and October with $r=0.30$ were both increasing and significant. It should be noted that the simulated temperature values based on two scenarios of $\mathrm{B} 1$ and $\mathrm{A} 2$ have very minor differences and few differences were seen in the trends of months for these two scenarios, therefore, to better understand this issue, one can refer to the output for December according to Fig. 4. 

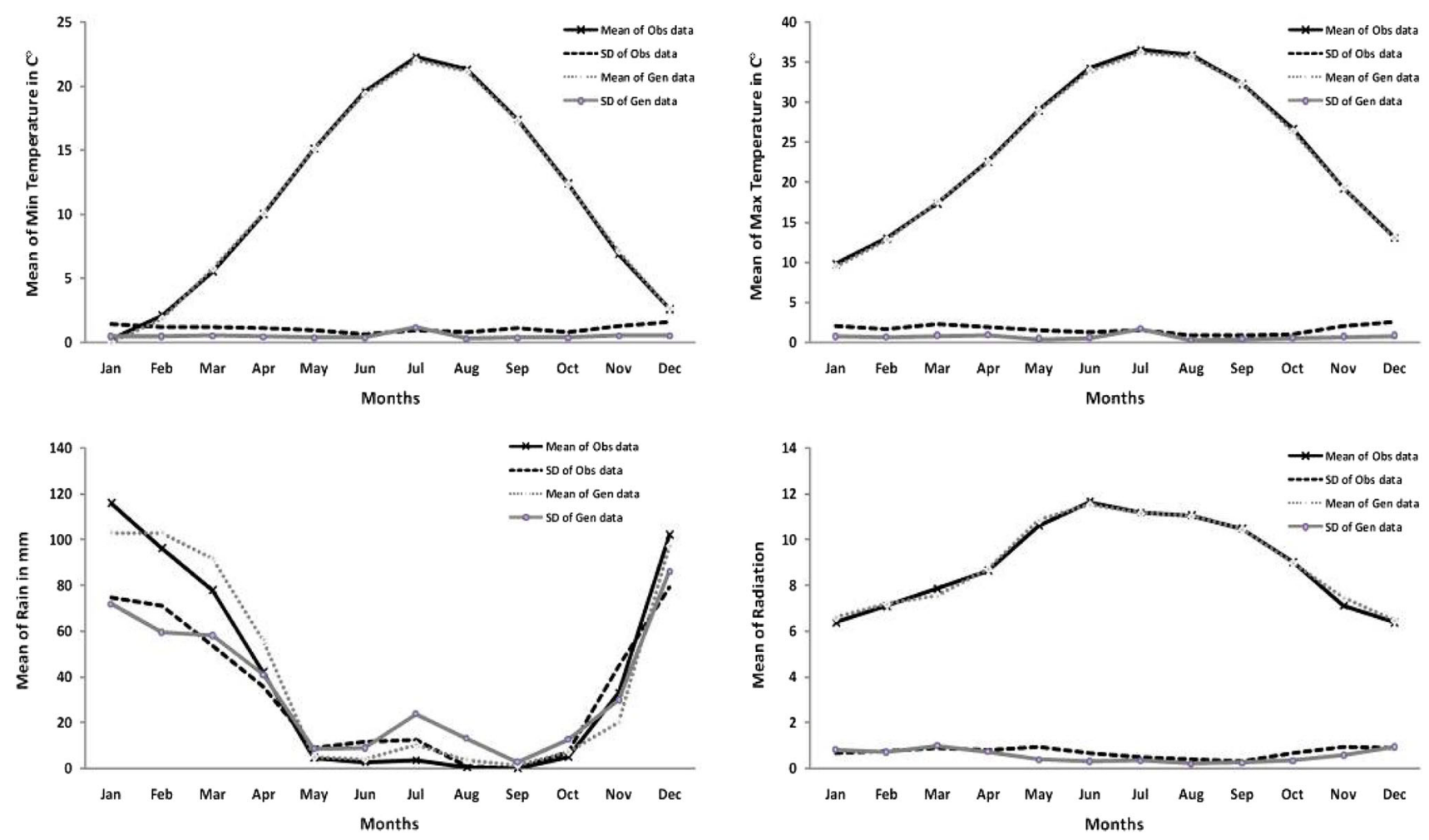

Fig. 2 The comparison of monthly average of climatic elements and the average standard deviation for the observational data and generated data

Table 3 Correlation coefficient of precipitation and temperature changes in the context of time based on the basic and simulated periods

\begin{tabular}{|c|c|c|c|c|c|c|c|c|}
\hline \multirow[t]{2}{*}{ Scenarios months } & \multicolumn{4}{|l|}{ Rain } & \multicolumn{4}{|c|}{ Temperature } \\
\hline & A1B & A2 & B1 & Observation period & A1B & A2 & B1 & Observation period \\
\hline Jan & -0.21 & -0.02 & -0.02 & -0.13 & -0.02 & 0.06 & 0.08 & 0.162 \\
\hline Feb & 0.10 & -0.01 & -0.01 & -0.43 & 0.02 & 0.23 & 0.24 & 0.70 \\
\hline Mar & 0.17 & 0.35 & 0.34 & -0.10 & -0.07 & -0.20 & -0.21 & 0.51 \\
\hline Apr & -0.38 & -0.14 & -0.14 & 0.05 & 0.13 & -0.04 & -0.05 & 0.13 \\
\hline May & 0.04 & -0.01 & -0.01 & -0.28 & 0.36 & -0.15 & -0.13 & 0.20 \\
\hline Jun & 0.00 & 0.15 & 0.15 & -0.30 & 0.09 & -0.15 & -0.15 & 0.47 \\
\hline Jul & 0.06 & 0.20 & 0.20 & -0.27 & -0.02 & -0.27 & -0.27 & 0.30 \\
\hline Aug & 0.05 & -0.01 & -0.01 & -0.09 & -0.03 & 0.23 & 0.26 & -0.26 \\
\hline Sep & -0.04 & -0.04 & -0.04 & -0.26 & -0.07 & -0.06 & -0.06 & -0.29 \\
\hline Oct & 0.21 & 0.19 & 0.19 & 0.23 & 0.06 & 0.30 & 0.30 & 0.07 \\
\hline Nov & -0.01 & -0.16 & -0.16 & -0.04 & -0.05 & 0.02 & 0.05 & 0.004 \\
\hline Dec & -0.07 & -0.07 & -0.07 & 0.05 & -0.01 & -0.22 & -0.20 & -0.15 \\
\hline
\end{tabular}

\section{Average discharge of the area}

As it can be seen Kor-chamriz basin has a drainage density of 1.77 and total length of the waterways is $2776.8 \mathrm{~km}$. confidently it can be said that this basin will have a severe hydrograph culmination point, this hydrological action is effective in soil erosion, morphological changes in waterways and flood rise (Table 4).

\section{Analysis of WS changes in the context of time}

As previously stated, the months with negative humidity fluctuation are prone to linear erosion especially gully erosion. So the index of soil humidity fluctuation can be an appropriate index for assessing areas or basins " potentiality for the linear erosion of flowing waters. As the results show long-term average of WS index both for basic period and 

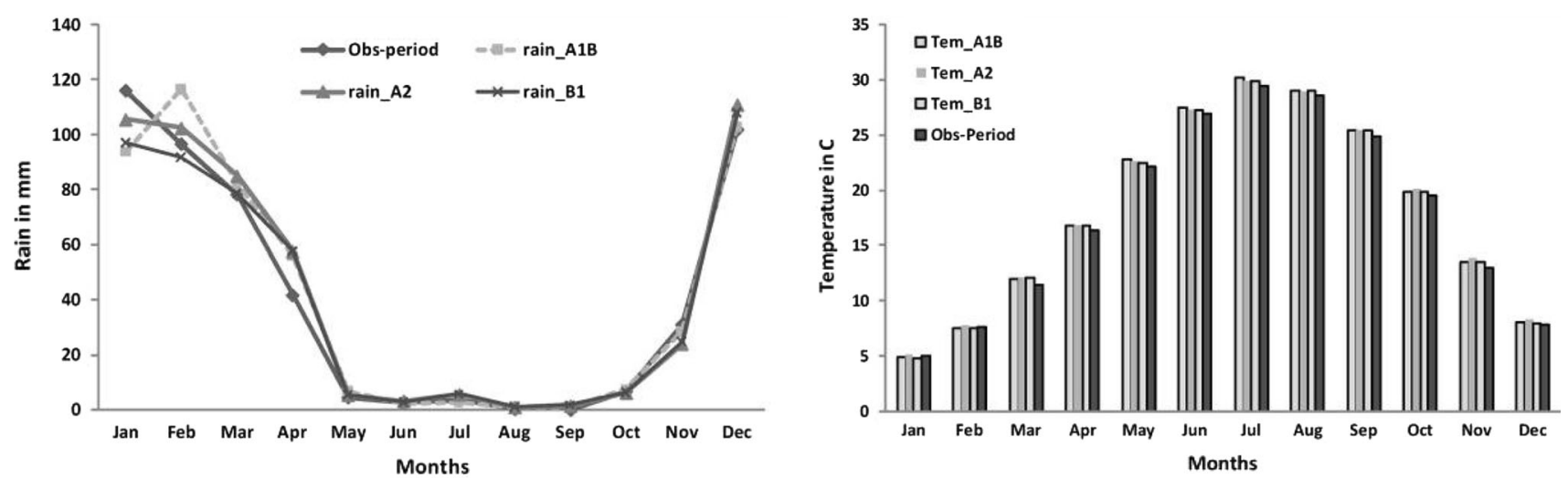

Fig. 3 Comparison of the average monthly rainfall amounts and average daily temperature of the basic period and the simulated period
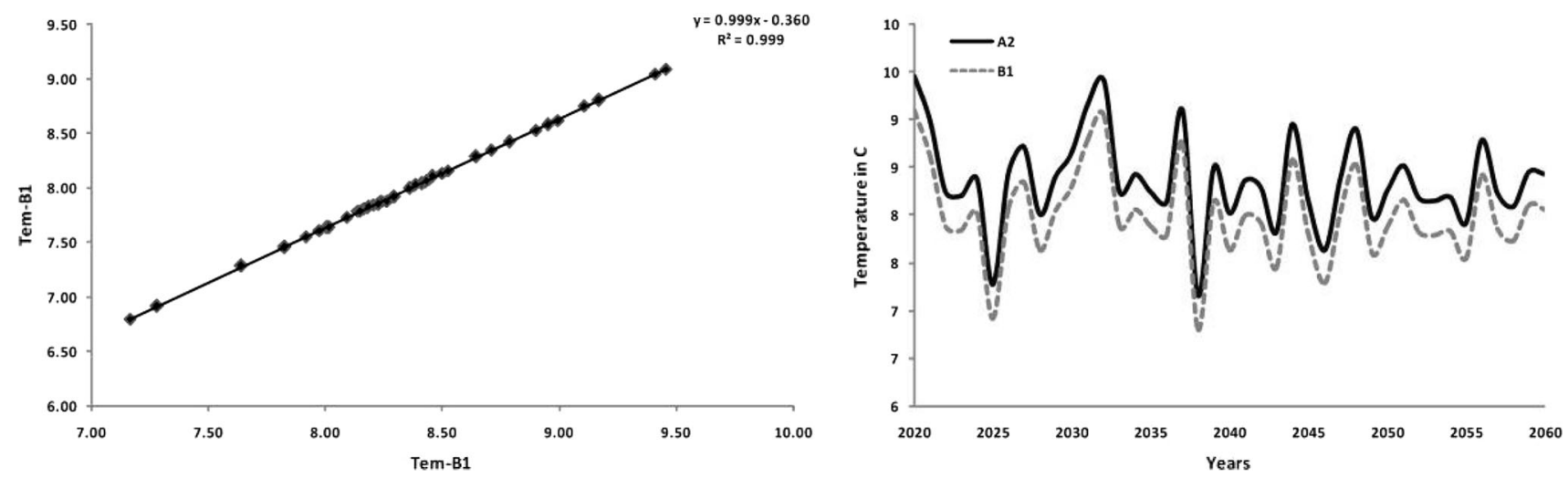

Fig. 4 Comparison of simulated values of monthly temperature of December according to A2 and B1 scenarios

Table 4 Morphometric data of drainage system, calculation of the slope and Debi of sub basins

\begin{tabular}{llllll}
\hline Watershed & Area $\left(\mathrm{km}^{2}\right)$ & The total length of waterways & Condensation drain $(\mathrm{km})$ & Slope $(\mathrm{persent})$ & Debi $(\mathrm{mm} / \mathrm{s})$ \\
\hline Kor-Chamriz watershed & 730 & 2776.8 & 1.77 & 5.36 & $590767 / 89$ \\
\hline
\end{tabular}

for future decades is indicating of negative values for all months. But what outputs show for the basic period indicates that cold months of the year especially January and February have the highest potential for the occurrence of gully erosion. On the other hand this potential for warm months of the year such as July, August, June and September compared to other months of the year is of the lowest value. Approximately similar results can be seen for the nest decades so that the maximum is seen in the cold months and in the warm months the minimum of gully erosion potential can be seen for Kor-chamriz basin. With regard to the comparison between the basic average longterm and different scenarios of climate change no significant difference can be seen among the data from May to November. But in all these months the occurrence of gully erosion for the basic period in comparison with the outputs of the next decades of three studied scenarios has been a little higher. The same conditions exist for April, March, December and even February, however, the difference between these two periods show a slight increase. In the following one of the interesting outputs is the increase in gully erosion occurrence for January compared to the basic period and other months of the year. All three studied scenarios especially A1B refers to the increase in gully erosion potential for the future decades compared to the basic period (Table 5) Reduction of WS amounts, mainly in hot and dry seasons causes the development of cracks in fine-grained formations. Disturbed earth's surface due to reduction of the protective effect of vegetation and trampling of soil by animals provides a situation for flowing waters to focus rapidly. So these cracks with first showers become a place for flowing waters and causes groove erosion and finally change into gullies in the basin that with respect to the focus of basin's rainfalls during the cold time 
Table 5 Shows the fluctuations in soil moisture estimates for the ling-term average of the basic period and the future decades along with the calibration correlation coefficient of long-term changes of temperature-humidity index during study periods

\begin{tabular}{|c|c|c|c|c|c|c|c|c|}
\hline \multirow[t]{2}{*}{ Scenarios Months } & \multicolumn{2}{|l|}{ B1 } & \multicolumn{2}{|l|}{ A2 } & \multicolumn{2}{|l|}{ A1B } & \multicolumn{2}{|c|}{ Observe-Period } \\
\hline & Correlation & Total average & Correlation & Total average & Correlation & Total average & Correlation & Total average \\
\hline Jan & $0.31 * *$ & -54.4 & $0.26^{*}$ & -51.2 & -0.20 & -54.2 & -0.09 & -48.7 \\
\hline Feb & 0.25 & -42.6 & 0.21 & -43.9 & -0.25 & -45.7 & -0.19 & -44.9 \\
\hline Mar & -0.18 & -40.6 & -0.14 & -40.1 & 0.09 & -40.8 & 0.13 & -41.5 \\
\hline Apr & -0.25 & -39.2 & -0.25 & -39.0 & -0.02 & -39.1 & 0.14 & -40.3 \\
\hline May & 0.24 & -38.9 & -0.05 & -39.0 & -0.17 & -39.1 & -0.02 & -39.3 \\
\hline Jun & $-0.54 * *$ & -37.6 & 0.02 & -37.5 & 0.15 & -37.6 & -0.09 & -37.7 \\
\hline Jul & $-0.82 * *$ & -36.8 & $-0.36^{* *}$ & -36.8 & -0.13 & -36.8 & -0.17 & -37.0 \\
\hline Aug & -0.07 & -37.2 & -0.14 & -37.2 & $-0.48 * *$ & -37.2 & -0.29 & -37.3 \\
\hline Sep & $0.58 * *$ & -38.2 & $0.69 * *$ & -38.2 & 0.08 & -38.2 & -0.29 & -38.4 \\
\hline Oct & 0.11 & -40.2 & -0.17 & -40.2 & 0.09 & -40.2 & 0.29 & -40.4 \\
\hline Nov & $0.27 *$ & -43.5 & $0.26^{* *}$ & -43.4 & -0.07 & -43.7 & -0.09 & -43.7 \\
\hline Dec & -0.15 & -43.0 & -0.23 & -41.7 & -0.14 & -42.6 & -0.07 & -43.8 \\
\hline
\end{tabular}

* Shows the significance level at $5 \%$ and ** shows significance level at the $1 \%$

of the year especially winter, it obviously can be seen that the maximum of gully erosion potential is in this period of the year. In the following the trend of WS index changes are shown for the basic period and the period of the future decades according to the Fig. 5. As it can be seen in Fig. 5, in most months, the fluctuations of the three scenarios have been the same up to 2005s but after 2005-2060, the difference between the fluctuations of the three scenarios have increased. Then the meaningfulness of these increasing and decreasing changes has been analyzed by Pearson correlation coefficient and the results are shown in Table 5. In the basic period for none of the studied months the changes are significant. But if the results of A1B scenario is considered, it can be noticed that only in August with $r=-0.48$ the decreasing trend is significant.

Therefore it is expected that in the future decades, the occurrence of gully erosion potential in this month increases based on the aforementioned scenario. In A2 scenario, for January, September and November, the significant and increasing (positive) trend of WS Index is indicative of a decrease in the gully erosion potential and for July, the decreasing (negative) trend is indicative of an increase in the occurrence of gully erosion potential. Finally, according to the B1 scenario, 3 months of January, September and November have increasing and significant trends while June and July have decreasing trends.

\section{Monitoring and simulation of erosion occurrence in the studied watershed}

At first the correlation between the two methods of Sepaskhah and Arnoldus was calculated that results confirm the significant relationship between the experimental methods with the actual data (Fig. 6). According to Fig. 6 it can be seen that the threshold of output values of two experimental models compared with the actual data of deposit is very little. Certainly its reason is ignoring of many other influential factors such as soil type, rocks, vegetation, land use, etc. to estimate the amount of the precipitation in the abovementioned formula. In Sepaskhah's formula, average long-term precipitation of the basin is 784 tons per hectare per year that this value is 4271 tones per hectare per year in Arnoldus method. But the actual data shows that actual amount of precipitation is 127,880 tons per hectare per year. The output of Arnoldus formula as a long-term average of the basic period of 1988-2010 covers only $19.5 \%$ of the actual deposition of the basin which is only $3 \%$ for Sepaskhah's method.

As the real quantities of deposition of the basin show the amount of deposition from the basin shows a high value which shows the loss of agricultural soil of the basin by the flowing waters. In the desired area due to rocks ' being rigid and hard, destruction requires a long time and process of destruction includes chemical and physical processes such as freezing, melting of ice and growing of plants roots. So that the physical destruction process in the region is more important than the chemical destruction process. This means that due to small cracks and tectonic activates, gaps and cracks emerge in the area then large pieces of stone change into small pieces and chemical destruction is done in the gaps and cracks of tectonic activities. In that area, regolith or air bedrock is seen this is a mixture of destructive materials including rocks, rubbles and finally the surface soil. In some areas mother rocks have been locally destroyed. The reason is that the slope is low (less than $25 \%$ ) and on the other hand proper vegetation 


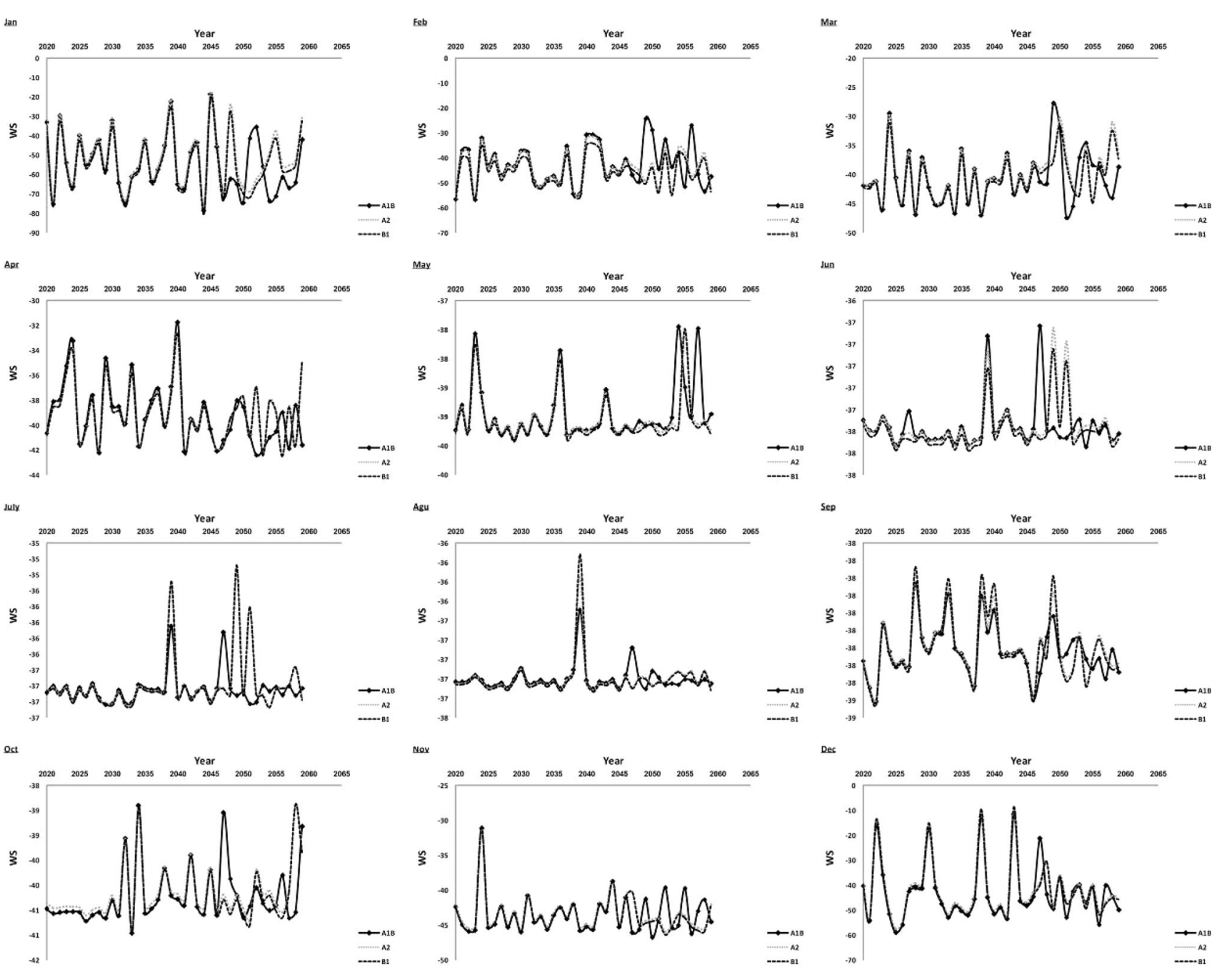

Fig. 5 Monthly changes of WS index for the period of 2020-2060 based on the three studied scenarios

includes plant species of Gon that prevents soil erosion and soil has been locally formed. In most areas this vegetation is destroying due to improper use and when the basin's surface is bare, fertile soils of the area will destroy. In the following based on Sepaskhah and Arnoldus models, sedimentation of the basin was analyzed according to different scenarios and for the future decades. Average long-term deposition of watershed based on the Arnoldus method reveals that this value is 5195 ton/hac/y after which two scenarios of A2 and B1 with values of 5140 and 4753 tons per hectare per year are in the next positions. But according to the Sepaskhah's formula, the maximum amount of rainfall erosion in the basin, with an average of 944 tons per hectare per year belongs to A1B scenario and A2 scenario with 930 and B1 scenario with 867 ton/hac/y are in the next positions. The interesting point is that under all scenarios and formulas presented in this study, the rainy erosion will decrease in the basin. So it is expected that the share of rainy erosion will be reduced from the whole actual erosion of the basin (Fig. 7).

\section{Conclusion}

Land is considered as the national wealth of each country and region and by applying appropriate management it must be tried for its sustainable development. One of the threats to this vital element is the problem of erosion of watersheds and the destruction of soils. This issue gets more important when the role of climate change will also be added to it. Therefore, in this study the effect of climate change on the gully erosion potential of Kor-chamriz watershed was studied for the period of 2020-2060. At first the results of modeling of climatic components show that although there has been no significant change in temperature and monthly precipitation patterns for the future 
Fig. 6 The correlation between the two methods of Arnoldus Sepaskhah
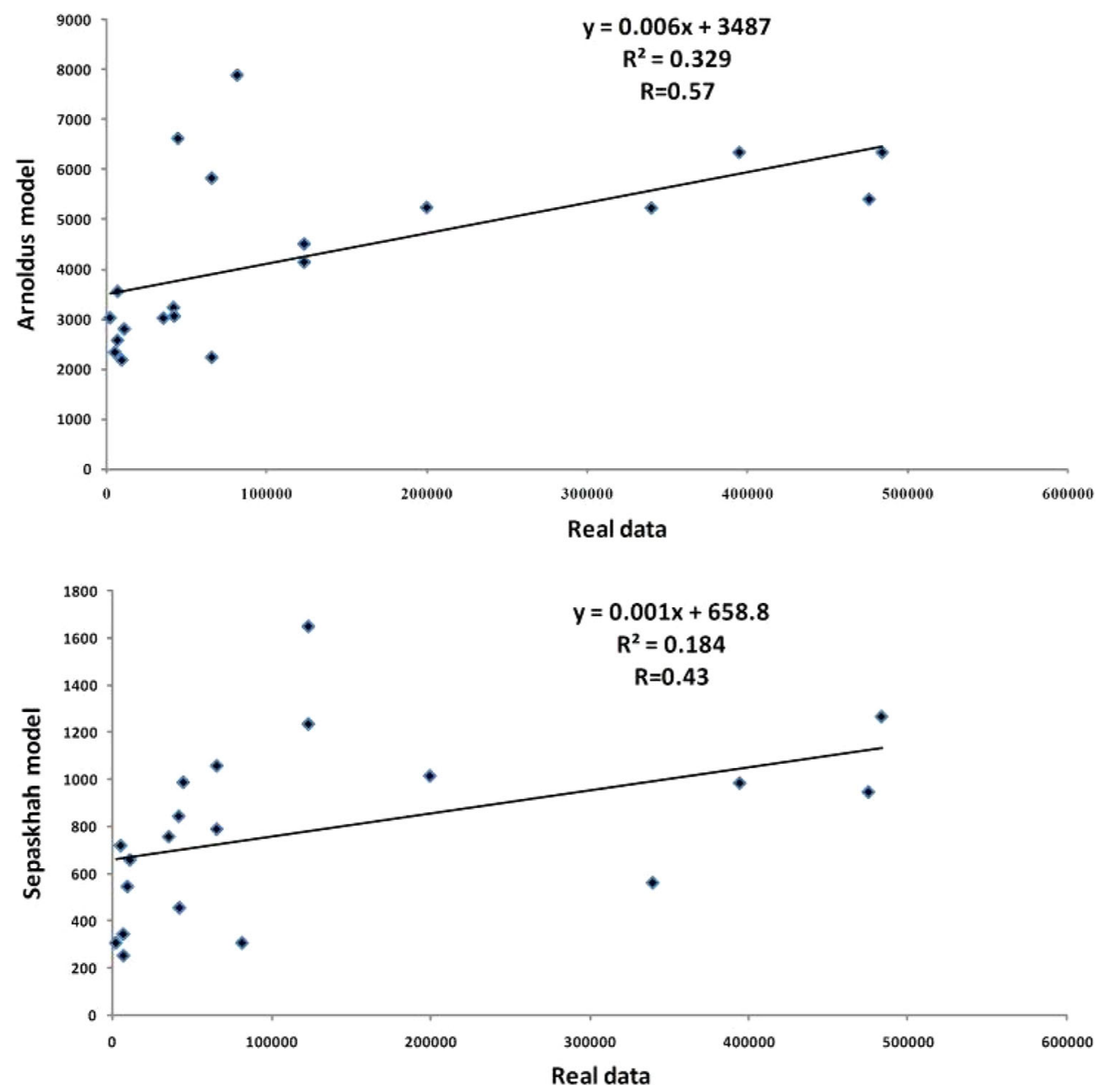

decades compared to the basic period, the annual temperature for the simulated period will increase between 0.32 and 0.51 degrees compared to the basic period. On the other hand, for two A1B and A2 scenarios, annual rainfall changes will increase by 18 and $24.5 \mathrm{~mm}$ respectively compared to the basic period. Although monthly precipitation change for most months is not significant, but trend changes for April is decreasing and it is increasing and significant for March. In this study, soil moisture model was used to analyze gully erosion potential. The findings of this section show that for the future decades as the basic period, the highest potential of gully erosion has focused on the cold months of the year. But for the future decades, in most months gully erosion potential decreases compared to the basic period but this situation in January is so that gully erosion potential will intensify for the future decades. Also in this study to assess changes in rainy erosion, two formulas of Sepaskhah and Arnoldus were used. But for the analysis of two proposed models, their results for the basic period were compared with the actual measured data of deposition from the basin. Findings confirm the significant relationship between the experimental methods with the actual data. Interestingly based on the long-term average of the basic period of Arnoldus method, the ratio of rainy erosion to the actual data has been $19 \%$ which was $3 \%$ in Sepaskhah's method. Therefore, due to the decline in rainy erosion based on the three proposed scenarios, it is expected that the share of this erosion decrease compared to the total erosion of the basin. But it should not be forgotten that the rainy erosion is a small part of the overall erosion of the basin. In the end, it is important to note that the aim of the present study was to assess the role of climate change on the rainy erosion so in order to achieve a comprehensive vision of the condition of erosion occurrence in the basin by anticipating the future decades other factors affecting the basin's erosion and deposition such as changes in land use and vegetation, the variability of the erosion from the basin be modeled in order to take more appropriate strategies and better management techniques to deal with the erosion of Kor-chamriz watershed. 
Fig. 7 Modeling of the rainy erosion for the future decades according to different scenarios of climate change
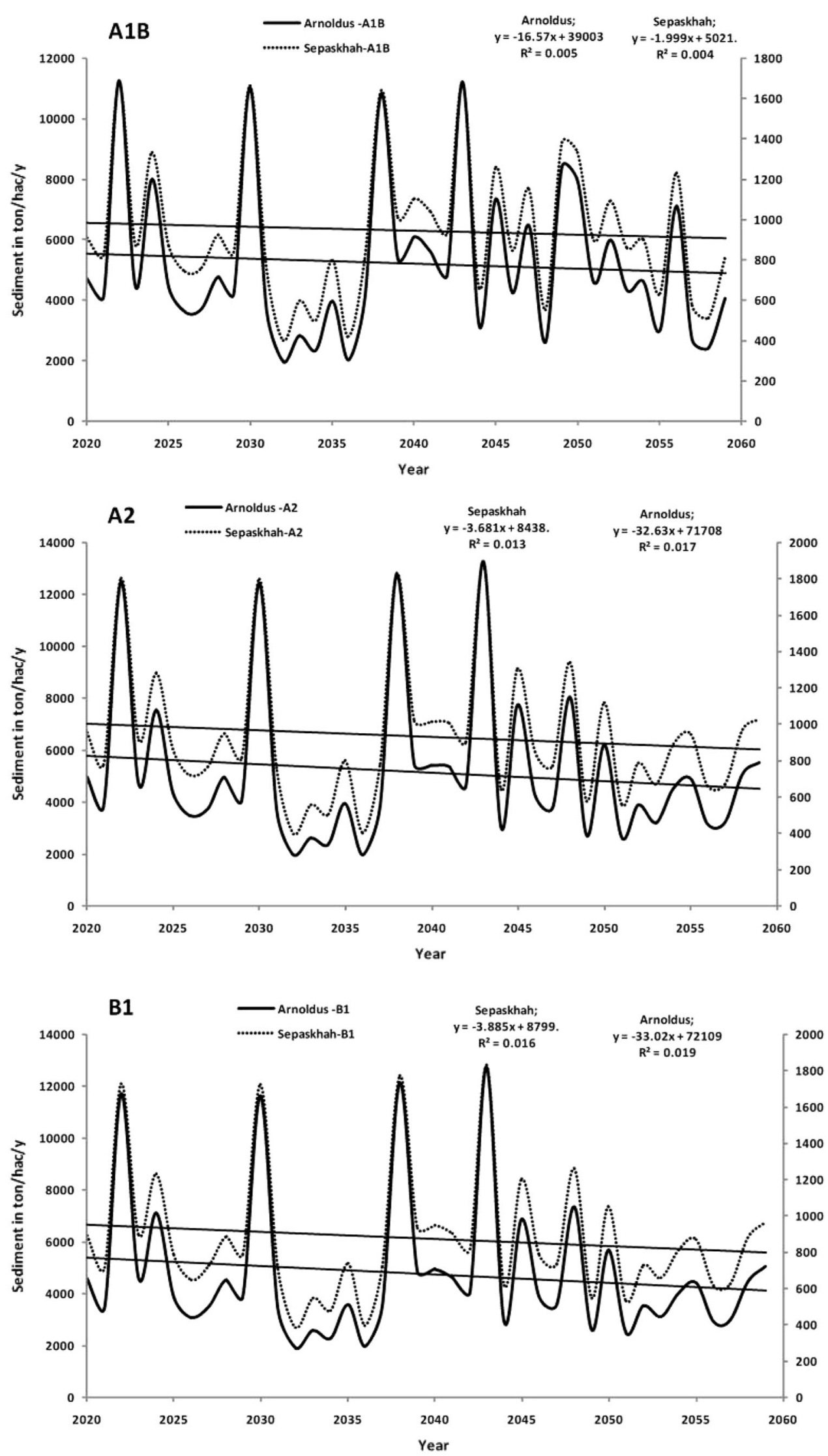


\section{References}

Archibold OW, Levesque LMJ (2003) Gully retreat in a semi-urban catchment's in saskatoon, Saskatchewan. Applied geography 23:261-279

Arnoldus HMJ (1980) An approximation of the rainfall factor in the Universal Soil Loss Equation. In: De Boodt M, Gabriels D (eds) Assessment of erosion. FAO Land and Water Deveopment Division, Wiley, England, pp 127-132

Babaeian I, Modirian R, Karimian M (2007) Sensitivity analysis of different convection schemes and center domains for numerical simulation of winter precipitation over Iran. J Aerosp Sci Technol 4(2):33-42

Bouchank H, Felfoul MS, Boussema MR, Snane MH (2009) Slope and rainfall effects on the volume of sediment yield by gully erosion in the Souar lithologic formation (Tunisia). catena 78:170-177

Cheng H, Y Wu, Zou X, Si H, Zhao Y, Lin D, Yue X (2006) Study of ephemeral gully erosion in a small upland catachment on the inner-Mongolian Plateau. Soil Tillage Res 90:184-193

Gabet Emmanuel J, Bookter Andy (2008) A morphometric analysis of gullies scoured by post-fire progressively bulked debris flows in southwest Montana, USA. Geomorphology 96(3-4):298-309

Gabris Gy, Kertesz A, Zambo L (2003a) Land use change and gully formation over the last 200 years in a hilly catchment. Catena 50:151-164

Gabris GY, Kertesz A, Zambo L (2003b) Land use change and gully formation over the Last 200 years in a hilly catchment. Catena 50(2):151-164

Hasan A (2000) Applied geomorphology. University of Tehran Press, Tehran, p 688

Kasali Mio (2006) Channel processes following land use changes in a degrading steep, headwater stream in North Isla (nd, New Zealand). Geomorphology 81(2006):421-439

Kheir RB, Wilson J, Deng Y (2007) Use of terrain variables for mapping gully erosion susceptibility in Lebanon. Earth Surf Landf 32:1770-1782
Kirkby MJ, Bracken LJ (2009) Gully processes and gully dynamic. Earth Surf Process Landf 1851:1841-1851

Kirkby MJ, Bull LJ, (2000) Some factors controlling gully growth in fine-grained sediments: a model applied in Southeast Spain. Elsevier. Catena. 40:126-146

Lucà F, Conforti M, Robustelli G (2011) Comparison of GIS-based gullying susceptibility mapping using bivariate and multivariate statistics: Northern Calabria, South Italy. Geomorphology 134:297-308

Oostwoud Wijdenes DJ, Bryan R (2001) Gully-head erosion processes on a semi-arid valley floor in Kenya: a case study into temporal variation and sediment budgeting. Earth Surf Proc Land 26(9):911-933

Posesen J, Nachtorgale J, Verstrac G (2003) Gully erosion and environmental change: importance and research needs. Cantana 50:91-133

Roshan GR, Grab SW (2012) Regional climate change scenarios and their impacts on water requirements for wheat production in Iran. Int J Plant Prod 6:239-266

UNEP (1994) United Nations Convention to Combat Desertification, United Nations Environmental Programme, Geneva

Valentin C, Poesen J, Li Y (2005) Gully erosion. Impacts factors and control. Catena 63:132-153

Vanwalleghem T, Van Den Eeckhaut M, Poesen J, Govers G, Deckers J (2008) Spatial analysis of factors controlling the presence of closed depressions and gullies under forest: application of rare event logistic regression. Geomorphology 95:504-517

Whitford JA, Newham LTH, Vigiak O, Melland AR, Roberts AM (2010) Rapid assessment of gully sidewall erosion rates in datapoor catchments: a case study in Australia. Geomorphology 118(2010):330-338

Zachar D (1982) Soil erosion. Elsvier scientific publishing company, UK, p 584

Zucca GT, Canu A, Della Pertua R (2006) Effects of lands use and landscape on spatial distribution and morphological. Features of gullies in an agropastoral area in Sardini (Italy). Catena 68:86-95 